\title{
Muito mais do que um dicionário do corpo: um dicionário para o corpo
}

ANDRIEU, B.; BOETSCH, G. (Org.).

Dictionnaire du Corps.

Paris: CNRS, 2008.

| ${ }^{1}$ Rafael da Silva Mattos |

${ }^{1}$ Professor adjunto do Instituto de Educação Física e Desportos da UERJ. Pesquisador do Grupo de Pesquisa CNPq Racionalidades Médicas e Práticas de Saúde. Endereço eletrônico: profmattos2010@gmail.com.

Escrever uma resenha sobre um dicionário pode parecer algo inusitado ou até mesmo desnecessário. No entanto, a riqueza do Dicionário do Corpo (Dictionnaire $d u$ Corps) não pode ser negligenciada. Trata-se de uma obra de 2008, organizada por dois grandes autores como Bernard Andrieu e Gilles Boëtsch.

Bernard Andrieu é professor de epistemologia do corpo e de práticas corporais na Universidade Henri-Poincaré, Nancy, e autor de vários livros. Gilles Boëtsch é antropólogo e diretor de pesquisas na França. A obra ainda contém um prefácio escrito por Michel Blay, diretor de pesquisa do Centre National de la Recherche Scientifique, França. Professores de universidades brasileiras também contribuíram para a obra, tais como: Francisco Ortega, da Universidade do Estado do Rio de Janeiro (UERJ); Carmen Lúcia Soares, da Universidade Estadual de Campinas (Unicamp); Ana Márcia Silva, da Universidade Federal de Santa Catarina (UFSC); e Maria Simone Schwengber, da Universidade Federal do Rio Grande do Sul (UFRSG), entre outros.

A obra contém mais de 200 verbetes atualizados e importantes para pesquisas que utilizam teorias, conceitos e categorias das ciências humanas e sociais. $\mathrm{O}$ dicionário constitui um verdadeiro desafio científico, já que conduz a uma releitura e uma reelaboração de diversos conceitos, tais como: alimentação, anorexia, ascese, aborto, beleza, biopoder, body-building, bulimia, clonagem, culto ao corpo, dietético, ética, feminismo, juventude, movimento, obesidade, práticas corporais, ritual, saúde, sexualidade, tatuagens, técnicas corporais, entre outros verbetes. Possui ainda uma riqueza adicional, pois cada verbete contém referências bibliográficas a que o leitor pode ter acesso - conforme seu interesse 
- num momento posterior. Todos os verbetes são fundamentados em autores que os discutem com profundidade teórica.

O verbete "biossubjetividade", por exemplo, analisado por Bernard Andrieu, ressalta que o corpo é uma matéria que se desenvolve num contexto não apenas cultural, mas biocultural. O corpo humano é biocultural porque resulta da interação de sua carga genética (genótipo) com um meio sociocultural (fenótipo) que ele incorpora à medida que vai se constituindo e se regulando, se adaptando, ao mundo exterior e às suas representações.

Nem inteiramente individual, nem estritamente social, o corpo humano é o resultado de uma construção simbólica e de uma invenção subjetiva segundo as percepções e as representações individuais e coletivas. Não há estrutura social que por si e em si modele o corpo, como não há ação social corporal que sozinha seja capaz de produzir mudanças sociais. "Estrutura e ação", "determinação e agenciamento" são termos que aparecem na literatura para dar conta desse objeto de estudo político, socioantropológico, filosófico e epistemológico chamado "corpo". Mudando o corpo, nós freamos a temporalidade biológica, seja retardando o envelhecimento, seja completando os efeitos do tempo com uma renovação do espaço do corpo. O corpo, enquanto ser vivo subjetivo, é sempre de uma intensidade, de uma temporalidade e de uma espacialidade que ninguém pode escapar. Mudando o corpo, mudamos nosso ser. Os estudos sobre a bioascese e as bioidentidades tratam dessa questão. Mudando seu corpo, o sujeito se descobre móvel, se descobre no pleno devir. Mais do que se construir para atingir um ideal estético ou funcional, o sujeito deseja se movimentar para participar do mundo que o cerca.

Outro verbete importante que merece nossa atenção (já que não iremos abordar nesta resenha cada verbete da obra) em um dicionário do corpo é o verbete "bodybuilding”. Em uma sociedade que cultua cada vez mais a aparência corporal, Philippe Liotard, professor da Universidade de Lyon, analisa o body-building como o conjunto de atividades físicas que visam modelar o corpo através de um esforço sistemático e analítico dos diferentes grupos musculares. Significa, no sentido estrito, a construção muscular do corpo. $\mathrm{O}$ uso do termo inglês implica a ideia de que o corpo pode ser construído como se constrói uma casa, por exemplo.

Essa prática de modelagem muscular nasceu na Europa por volta do século XIX, com a finalidade de produzir corpos fortes e sadios. Os ginastas da época 
inventaram uma maneira racional de se exercitar para fortalecer o corpo e modelar a anatomia. Nascia a educação física higienista e eugênica. Muitos confundem o body-building com o fitness ou halterofilismo. Liotard argumenta que, no sentido mais radical da palavra, o body-building corresponde a uma dimensão institucionalizada da prática com concursos, espetáculos e profissionalização.

Assim compreendido, o body-building necessita de um engajamento obsessivo e cotidiano numa prática de controle em todas as dimensões da vida humana (alimentação, sono, sexualidade, horário e frequência de treinamento, etc.). Essa dimensão do body-building o submete a um imaginário da virilidade que se condensa na hipertrofia muscular (SABINO; LUZ, 2007). Não se trata somente de adquirir os signos anatômicos tradicionalmente associados à masculinidade. Trata-se de produzir uma imagem, de tentar se aproximar de um modelo de virilidade exacerbado pelos super-heróis do desenho ou dos cinemas. O corpo é metamorfoseado (VIGARELLO, 2005) de fora para dentro.

Outro verbete que merece nossa análise é "santé". O termo é apresentado e discutido pelo professor de filosofia Alexandre Klein. Saúde é definida como o bem-estar físico e psicológico do ser humano; o estado normal do organismo de um ser vivo implicando funcionamento regular, harmonioso, sem comprometer funções vitais, independentemente de anomalias ou de enfermidades. A saúde é ao mesmo tempo universal e cultural: universal porque todos os seres humanos e povos a buscam enquanto valor; cultural porque sofre variações históricas e sociais.

Alexandre Klein cita Georges Canguilhem, Kant, René Leriche, Claudine Herzlich, Lucian Sfez e Didier Fassin como autores fundamentais para a compreensão do conceito de saúde. A saúde é uma interação dinâmica do ser vivo com o meio em que vive. Essa compreensão dinâmica qualifica a saúde como equilíbrio ou harmonia. O bom estado de saúde é um processo de manutenção do equilíbrio homeostático do organismo. No entanto, já compreendemos que esse equilíbrio não se reduz ao biológico, mas incorpora a dimensão psicológica, social, cultural e até ontológica do sujeito.

Klein retoma uma expressão de Kant sobre a saúde, pois este filósofo afirma que a saúde é o sentimento presente da força vital ativa, argumentando que há aqui uma influência sobre o conceito da Organização Mundial da Saúde, de 1946, que afirma que a saúde é o estado completo de bem-estar físico, mental e social, e não somente ausência de doenças ou enfermidades. Klein não deixa de 
mencionar que as ciências médicas se desenvolvem progressivamente, oferecendo critérios objetivos de saúde através das biotecnologias. A imagem da saúde perfeita fica reduzida aos modelos estatísticos, contrariando contribuições clássicas para a compreensão da medicina como ciência que busca a ampliação da normatividade vital (CANGUILHEM, 2009) ou que busca a arte terapêutica (LUZ, 2005). A saúde perfeita aparece então como uma utopia para a população (SFEZ, 2001) ou como uma estratégia biopolítica (FOUCAULT, 1999, 2004a, 2004b).

O Dicionário do Corpo (Dictionnaire du Corps) é uma importante obra para alunos, professores e pesquisadores, mas não está isolado. Ele pertence a um conjunto de outros dicionários organizados e publicados pelo Centre National de la Recherche Scientifique da França. Na última página da obra, há uma lista com outros 12 dicionários.

Lembro-me que Deleuze e Guattari (1991) argumentam que a potência de um pensamento está na criação e utilização de conceitos. Um pensamento não é certo ou errado, mas forte ou fraco, ativo ou reativo. O pensamento não é medido pelo grau de verdade que ele possui, mas pela força, intensidade, vitalidade e imanência que ele possui. Se procuramos obras fidedignas e densas sobre conceitos que gravitam em torno do "corpo", nas ciências humanas, eis aqui uma: Dictionnaire du Corps.

\section{Referências}

CANGUILHEM, G. Le normal et le pathologique. 11 ed. Paris: PUF, 2009.

DELEUZE, G.; GUATTARI, F. Qu'est-ce que la philosophie? Paris: Minuit, 1991.

FOUCAULT, M. Les anormaux. Paris: Seuil, 1999. . Naissance de la biopolitique. Paris: Gallimard, 2004a. Securité, territoire, population. Paris: Gallimard, 2004b.

LUZ, M.T. Novos saberes e práticas em Saúde Coletiva: estudo sobre racionalidades médicas e atividades corporais. 2. ed. rev. São Paulo: Hucitec, 2005.

SABINO, C.; LUZ, M.T. Ritos da forma: A construção da identidade fisiculturista em academias de musculação na cidade do Rio de Janeiro. Arquivos em Movimento (Revista Eletrônica da Escola de Educação Física e Desportos - UFRJ). Rio de Janeiro, v. 3, n. 1, p. 51-68, jan.-jun. 2007.

SFE, L. L'utopie de la santé parfaite. Paris: PUF, 2001.

VIGARELLO, G. Années folles: le corps métamorphosé. Sciences Humaines, n. 4 (Femmes, Combats et Débats), nov.-dez. 2005. 